\title{
Bank's Hidden Negative Capital Before and After the Senior Management Change at the Bank of Russia'
}

\author{
Mikhail Mamonov, Center for Economic Analysis \\ and Short-Term Forecasting
}

\begin{abstract}
What was the size of hidden negative capital (HNC) in the Russian banking system before the Bank of Russia's senior management changed? Has the financial regulator's new, tougher, supervision policy launched in mid-2013 been productive in dealing with problems accumulated over recent years? This study attempts to provide first answers to these questions using Heckman selection models and solving a possible regulator's optimization problem using the data on Russian banks over the period from December 2009 to May 2017. The study results suggest that before the change of the Bank of Russia's senior management in mid-2013, the average level of HNC at banks operating in Russia was very high: 14\% of the banking system's total assets on each specific date, and fairly permanent in time. But as early as half a year after the Bank of Russia's senior management changed, the overall size of HNC started contracting rapidly, coming close to $4 \%$ by mid-2016. In the last 12 months of the time span under study the level of the HNC stabilized at 4\%. These estimates point to the high effectiveness of the new senior management's supervision policy. This policy has produced a strong indirect positive effect: large part of fragile banks have started addressing their problems without waiting for the Central Bank's intervention. The effectiveness of the Bank of Russia's new policy cannot be attributed to other factors such as macroeconomic stabilization or improvement and/or rising profitability of bank operations. Rather, when supervision policy was stepped up, these other factors were acting in the opposite direction.
\end{abstract}

Keywords: banks, hidden negative capital, fraudulent accounts, Bank of Russia, supervision policy

JEL: G21, P23, P34, P52

\footnotetext{
1 The study was carried out under a research grant № 16-36-60037 mol_a_dk from the Russian Fund for Fundamental Research (RFBR) in 2017.

The author is grateful to Oleg Solntsev and Anna Pestova for establishing a creative environment and discussing the study concepts. In addition, the paper was substantially improved thanks to comments by Ion Lapteacru and Simona Nistor in the course of a special session of the 19th Annual Conference of the International Network for Economic Research (INFER) at the Bordeaux University, France. The author acknowledges discussion of the paper with the participants of research seminars at the Laboratory for Macroeconomic Research of National Research University Higher School of Economics and the Finance Department of Higher School of Economics, II World Congress on Comparative Economics "1917-2017: Revolution and Evolution" (St Petersburg), and the 34th Symposium on Money, Banking and Finance at Nanterre University, France.
} 


\section{Introduction}

In recent years, the issue of hidden negative capital (HNC) at Russian banks has come to the fore in discussions on improving banking system stability, overshadowing such topics as nationalization of financial institutions, the falling number of regional banks, introduction of the countercyclical capital buffer or rising interest rates on banking loans to the real economy. ${ }^{2}$ Under the standard definition used in the literature and among financial regulators, $\mathrm{HNC}$ means a negative difference between a bank's total assets and its total liabilities (James, 1991; Kang et al., 2015; Cole and White, 2015), which is thus close to the concept of negative net worth. Why can such a negative difference arise and how long can it persist? The answer to the first question is that any economy, industry or an individual firm may, at any time, encounter negative productivity, income allocation or insolvency shocks (Bernanke and Gertler,1989) forming a negative financial cycle spiral persistent in time (Kiyotaki and Moore, 1997; Chen, 2001). The answer to the second question is that the period of HNC's persistence may be rather long for at least two reasons. On the one hand, from the perspective of the bank capital theory (Diamond and Rajan, 2000), a bank can operate with HNC until it loses the confidence of depositors, who, because of information asymmetry, may be unaware of its problems, continuing to replenish its liabilities, but as this asymmetry is overcome, an immediate deposit run and a license withdrawal by the regulator follow. (Diamond and Dybvig, 1983). On the other hand, any economy is subject to regulatory forbearance (examples from the US are in Wheelock and Wilson, 2000; Kang et al., 2015), with a regulator being unable to withdraw licenses for a multitude of reasons ranging from the high cost of overcoming information asymmetry to possible political pressure and a government budget deficit (Brown and Dinç, 2011).

The problem of banks' HNC in Russia could not fail to arise because of certain features of the system itself and those of economic agents.

First, economic agents - banks and their borrowers in this case - have a higher risk tolerance (compared with developed countries) leading to both higher returns on equity and higher volatility of these returns (implying more frequent and massive bank failures).

Second, the banking system itself is more dynamic due to its young age and undersaturation of key markets for banking services because of it.

Third, the Russian economy has an increased vulnerability vis-à-vis external shocks.

Fourth, the regulatory environment is not static, proposing to the system various innovations, which create adaptation costs for banks. All these peculiarities set the stage for the spreading and escalation of shocks, which, as pointed out in the above theoretical studies, give rise to $\mathrm{HNC}$ and make it impossible for the regulator to detect them immediately.

\footnotetext{
${ }^{2}$ We note that certain relationships can be found between any of these topics and the HNC, which are to be addressed in further studies.
} 
According to estimates using the Bank of Russia Bulletin data, from mid-2013 to mid-2017, the regulator discovered 2 trln rubles of HNC at a total of 227 banks (around $2.5 \%$ of the banking system's assets) ${ }^{3}$. In our previous study we estimated the overall size of yet-undetected $\mathrm{HNC}$ at 3.6\%-6.8\% of the banking system's assets as of mid-2016, the statistical detection threshold standing at 5\% (Mamonov, 2017b). This study provides a more in-depth analysis and poses the following questions:

1. What was the total amount of HNC accumulated by the time the Bank of Russia's senior management changed?

2. How stable was their overall level prior to mid-2013?

3. Did this level start declining after the Bank of Russia's senior management had changed, and if so how fast and what it stemmed from (a change in macro-, micro-, regulatory environment or altogether)?

Answers to these questions can shed light on whether the Bank of Russia's policy of cleaning the banking system from unfair players was effective or not. To provide answers to these questions, we will, following Mamonov (2017b), use the methods of Heckman selection models, allowing to evaluate the size of what is hidden and thereby address the problem of the sample selection bias (Heckman, 1979). Specifically, by using a fixed sample of banks with HNC detected by mid2016 (the fragile group), we will estimate the size of HNC at banks that were operating in each month from the start of 2010 to mid-2016 (backward forecasting) and from mid-2016 to mid-2017 (forward forecasting), i.e., in the variable reference group. Thus, what distinguishes this study is that rather than fix the sample composition at the end of the observation period (mid-2017) it forms the sample within the available time span, closer to its end (mid-2016), for the current experience in detecting HNC to be sufficient for their backward and forward (for the immediate future) forecasting. It is well known that balance sheet fraud gets ever more sophisticated, as banks are well aware that, learning from past experience, the Bank of Russia keeps improving its supervision policy.

The results of this study suggest that the efforts of the Bank of Russia's new senior management to uncover HNC at banks have borne fruit: apart from the direct positive effect (uncovering of HNC and license withdrawals) this has also produced an indirect positive impact: banks operating in Russia have started scaling down balance sheet fraud without waiting for the Bank of Russia's intervention.

This paper comprises the following sections: Section 2 explains the methodology of the study. Section 3 describes the data used. Section 4 presents the results of regression analysis and estimation of $\mathrm{HNC}$ at banks still operating during the period. Section 5 concludes.

\footnotetext{
${ }^{3}$ At the time when this paper was prepared official statistics on the major developments of the second half of 2017 - uncovering HNC at some of the top-10 banks (the Otkritie Financial Corporation and Binbank), were still unavailable.
} 


\section{Methodology of detecting and backward and forward forecasting of banks' hidden negative capital}

Detection of HNC, to the best of our knowledge, has not been addressed in academic literature on financial stability. Previous research considered determinants of negative capital in already failed banks (James, 1991; Kang et al., 2015; Balla et al., 2015; for detailed reviews see Mamonov, 2017a, b). Therefore, hereinafter we will concentrate on the methodology of $\mathrm{HNC}$ detection at different points of time.

In our previous study, we described the functional of Heckman selection models which allows - at each given probability threshold — evaluating the size of HNC at any of still operating banks through comparison with the sample of banks where the regulator has previously uncovered such HNC (Mamonov, 2017b). We will refer to the sample of still operating banks as the reference group, while banks where HNC have already been detected will be termed the fragile group. In this study we will fix the fragile group composition as of mid-2016 and vary the reference group's composition in the December 2009 - June 2016 time span for the purpose of backward forecasting of HNC and in the July 2016 - May 2017 horizon to perform forward forecasting of HNC. In this manner, we will run a series of $7 \times 12+6=90$ Heckman selection models - one model for each month in the period from December 2009 to May 2017. Heckeman selection model will be given by:

$$
\begin{gathered}
D_{i t}=\alpha_{1}+\sum_{l=1}^{L} \beta_{1, l} \cdot B S F_{l, i t-k}+\delta \cdot \ln T A_{i t}+\rho_{1} \cdot M A C R O_{j, t}+\varepsilon_{1, i t+\tau}>0 \\
\frac{N N W_{i t+\tau}}{\text { Capital }_{i t-1}}=\alpha_{2}+\sum_{l=1}^{L} \beta_{2 . l} \cdot B S F_{l, i t-k}+\rho_{2} \cdot M A C R O_{j, t}+\varepsilon_{2, i t+\tau}
\end{gathered}
$$

where $i$ is the index of a bank which may belong to the fragile or reference group; $t$ the varying time of model estimation $(t=1,2, \ldots, 90) . N N W_{i t+\tau}$ (Negative Net Worth) is the size of the HNC (bln rubles) uncovered by the Bank of Russia $\tilde{t}+\tau$ time after the license withdrawal ( $\tau=1,2$ months) from the banks of the fixed fragile group, or the value to be estimated for still operating banks from the variable reference group. Therefore, for banks from the fragile group $t=\tilde{t}$, where $\tilde{t}=43,44$, ..., 79, which corresponds to the time span from June 2013 (the Bank of Russia's senior management change) to June 2016 in which we fixed the composition of the fragile sample. Capital $_{i t-1}$ is the stock of a bank's equity capital on its balance sheet. $D_{i t}$ is the likelihood of detecting nonzero HNC (a latent variable). $B S F_{l, i t-k}$ are microeconomic control variables reflecting differences across banks by parameters such as the structure of their assets and liabilities, the size of business and risk tolerance, the scale of balance sheet fraud based on indirect signs (an increased reliance on taking household deposits combined with an increased reliance of the business model on corporate lending, an increased turnover of funds in 
correspondent accounts with the Bank of Russia along with a decreased repo liabilities turnover (for details see Mamonov, 2017b). $k=3$ months, similarly to the previous study. $M A C R O_{j, t}$ is a $j$-th control variable for the macroeconomic change (annual GDP growth rate, unemployment, etc.). $\varepsilon_{1, i t+\tau}$ and $\varepsilon_{2, i t+\tau}$ are regression errors of the selection equation (1) and size equation (2), respectively.

It should be reminded that Heckman model is deemed to be identified, while an incomplete sample bias is deemed proved if the following two conditions are met: a variable is found which has a substantive and statistically significant effect on the selection process but has no impact on size; a statistically significant correlation of errors $\varepsilon_{1, i t+\tau}$ and $\varepsilon_{2, i t+\tau}$ is shown. If these conditions are met then consistent estimates of coefficients of equations (1)-(2) are only possible using the Heckman one-step maximum likelihood (ML) procedure or the effective Heckman two-step method. In the former case, equations (1)-(2) are estimated within a system, and it takes certain time to reach convergence, which is not guaranteed in the general case. In the latter case, equation (1) is estimated as a usual probitmodel, used to calculate the nonselection hazard which is equal to the ratio of the density function value to that of the distribution function in each observation point. Then this variable is added to equation (2) as a supplementary regressor and its statistical significance is tested. If one of the two conditions is not satisfied, a consistent estimation is possible using any available technique. We will use the two-step Heckman method in the Stata package which does not require time for convergence to be reached.

Thus equation (1) prescribes the selection rule, i.e., the procedure for attributing each bank in either the fragile or reference group, while equation (2) determines the relationship between the relative size of the HNC and the fundamentals. Equation (2) enables the HNC size to be estimated in each of the 90 months for each bank from the reference group. The mechanism is so structured that this will be a nonzero value, but it is probabilistic and should be compared with the probability of detecting HNC which is estimated by equation (1). This means that we need a probability threshold, and if it is exceeded we will believe that the size of the HNC estimated by equation (1) is indeed nonzero. This in turn requires threshold quantification.

We will quantify the probability threshold using the out-of-sample forecasting procedure and, unlike our previous study, the estimation of the regulator's utility function for each possible value of this threshold, i.e., ranging from $1 \%$ to $100 \%$. Formally, we will move from the upper bound of $t$ period backwards (end-2015), carry out estimation using model (1)-(2), calculate the size of HNC at the banks from the reference group and compare them with banks where HNC were actually found and license withdrawn in the subsequent half a year. In addition, we will estimate type I and type II standard errors - cases when the model predicted nonzero HNC but they were not found and those when the model did not predict nonzero HNC but the regulator detected them. The regulator's utility function will 
be defined as one where the regulator wishes to maximize the share of accurately predicted events of HNC presence and absence, i.e., the share of correct attribution of banks to each of the two groups under analysis. We do not know the regulator's preferences regarding the importance of banks' correct attribution to the first or second group, which makes us prescribe them in a judgement-based manner. We will assume that the regulator may be (a) indifferent regarding the attribution of banks to the first or second group (weights $\gamma_{1}=\gamma_{2}=0.5$ ), (b) attaches greater importance to the correct attribution of banks to the fragile group $\left(\gamma_{1}=0.75\right.$ and $\left.\gamma_{2}=0.25\right)$, (c) views the correct attribution to the reference group as having a greater value $\left(\gamma_{1}=0.25\right.$ and $\left.\gamma_{2}=0.75\right)$. Therefore, the problem of maximizing the regulator's utility function is given by:

$$
\begin{gathered}
U\left(p, \gamma_{1}, \gamma_{2}\right)=\gamma_{1} \frac{A(p)}{A(p)+B(p)}+\gamma_{2} \frac{D(p)}{C(p)+D(p)} \rightarrow \max \\
\text { under constraints } \gamma_{1}+\gamma_{2}=1 \\
0 \leq \gamma_{1} \leq 1 \text { and } 0 \leq \gamma_{2} \leq 1
\end{gathered}
$$

where $U\left(p, \gamma_{1}, \gamma_{2}\right)$ is the value of the regulator's utility function depending on the chosen $p$ threshold of uncovering HNC and the regulator's preferences regarding the attribution of a bank to one or the other group, $\gamma_{1}$ and $\gamma_{2}$. The events $A(p)$, $B(p), C(p)$ and $D(p)$ are standard for the literature on bank failures (DeYoung and Torna, 2013) and the signaling approach (Kaminsky and Reinhart, 1999). Their meaning is disclosed in Table 1.

Table 1. Predictive characteristics of selection models for bank HNC required for constructing the regulator's utility function

\begin{tabular}{l|ccc} 
& \multicolumn{3}{|c}{$\begin{array}{c}\text { HNC is predicted at } t_{0} \text { time using detection } \\
\text { probability threshold equal to } p(p=\mathbf{1} \%, \ldots \mathbf{1 0 0 \%})\end{array}$} \\
\hline & & yes & no \\
\hline $\begin{array}{l}\text { HNC detected within time } \\
\text { span }\left(t_{0}, t_{0}+k\right)\end{array}$ & yes & $\mathrm{A}(\mathrm{p})$ & $\mathrm{B}(\mathrm{p})$ \\
\cline { 2 - 4 } & no & $\mathrm{C}(\mathrm{p})$ & $\mathrm{D}(\mathrm{p})$ \\
\hline
\end{tabular}

In solving the optimization problem (3)-(5) we obtain the value of $p^{*}$ probability threshold and those of the regulator's preferences $\gamma_{1}^{*}$ and $\gamma_{2}^{*}$ providing for the maximum regulator's utility function.

Then, using the obtained $p^{*}$ optimal threshold, backward and forward forecasting of the values of HNC for banks from the reference group will be carried out. These estimates will then make it possible to analyze the effectiveness of the Bank of Russia's banking sector recovery policy. 
Concluding this section, we point out that, to our knowledge, Heckman type (1) and type (2) selection models were only used to analyze bank HNC in Balla et al. (2015) using US bank data for the periods of the 1980s and 2000s banking crises. That study however focused on the consistent estimation of negative capital determinants rather than that of their hidden size at American banks that were still in operation. With regard to Russia's banking system, Drobyshevsky and Zubarev (2011), Karminsky and Kostrov (2013), Peresetsky (2013) and many others studied the probability of bank failures using logit- or probit-models but did not seek to find out the size of HNC at banks whose licenses had been withdrawn.

\section{Dataset}

Official data on the size of HNC revealed by the Bank of Russia at troubled banks are published in the Bank of Russia's Bulletin some time after a bank's failure in case the actual value of assets is smaller than the value of liabilities in each respective bank. This study uses the same list of banks with HNC found after the Bank of Russia's senior management changed in mid-2013 until July 2016 as Mamonov (2017b) did. These are 167 banks from the fragile group fixed in time for the purposes of our study (see Section 2). The reference group varying in time for the same purposes was made up of around 1020 banks at the beginning of the time span under analysis, December 2009, dwindling to 576 banks at the end of the period, May 2017. Data for forming the composition of control factors in equations (1) and (2) were obtained from standard sources, which are Forms 101 containing monthly balances of credit institution assets and liabilities that are disclosed on the Bank of Russia website. ${ }^{4}$ Then the outliers - data from the 1st and 99th percentiles for all the relative variables in equations (1) and (2), were eliminated. As a result, there were 152 banks left in the fragile group, while the resulting number for the reference group was 661 banks at the start of the time span under analysis, 735 in mid-2013 and 508 at the end of the period (the significant contraction in the number of observations at the start of the period stemmed from the shortage of observations for some individual indicators).

Descriptive statistics are presented in Table 2 as of the start of the period in question, mid-2013, when the Bank of Russia's senior management changed, and as of the end of this time span. Since Heckman selection model is estimated simultaneously using data from both groups, the descriptive statistics are presented as a total for the fragile and reference groups. Moreover this study does not seek to identify differences between these groups (this was done in the previous study, Mamonov (2017b). We are however interested in the variables themselves because they determine the predictive power of the selection model (1)-(2) and, accordingly, forecasts for the size of HNC. Therefore, we will look at the variables in somewhat more detail.

\footnotetext{
${ }^{4}$ See: https://www.cbr.ru/credit/forms.asp
} 
Table 2. Descriptive statistics: before, during and after the Bank of Russia's senior management change (as a total for the reference and fragile groups)

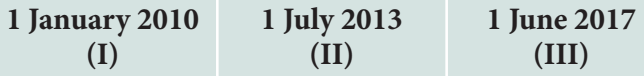

Bank-level explanatory variables, lag = 3 months before license withdrawal

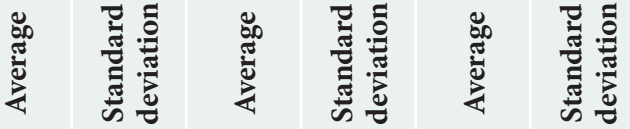

Household deposits ${ }^{\mathrm{a}}>$

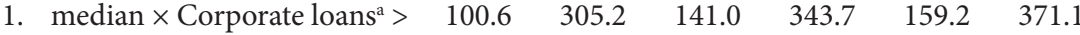
median

2. Corporate loans $>$ median $x$

2. Profit $/$ capital $<$ median

$\begin{array}{llllll}-4.4 & 17.0 & -12.1 & 24.8 & -15.6 & 44.0\end{array}$

3. Loan loss provisions $>$ median $\times$ NPL $<$ median

$5.0 \quad 10.7$

5.3

$10.5 \quad 7.2$

14.7

Monthly turnovers

4. in corresp acnts with Bank

$\begin{array}{llllll}61.9 & 286.2 & 299.5 & 3332.1 & 298.6 & 3422.2\end{array}$ of Russia, \%

5. Monthly turnovers of repo

liabilities, $\%$

$1.1 \quad 4.1$

1.5

4.1

12.7

258.0

6. Household loans / Assets, $\%$

$15.0 \quad 14$.

7. Absolutely liquid assets / Assets, \%

14.6

4.6

14.5

11.7

12.9

15.

8. Corporate securities /

Assets, \%

0.8

2.4

1.1

3.3

0.5

1.9

9. Loans due from interbank market / Assets, \%

$6.5 \quad 10.0$

10.0

8.3

$\begin{array}{ll}11.5 & 9.8\end{array}$

13.8

10. Foreign liabilities / Liabilities, $\%$

4.2

10.0

4.2

9.7

3.5

9.4

11. Capital / Assets, \%

20.

12

183

12.9

$19.9 \quad 13.4$

12. Loan loss provisions / Loans, \%

$\begin{array}{llllll}12.9 & 11.5 & 13.4 & 20.9 & 26.5 & 52.8\end{array}$

13. Annual asset growth rate,

14. Assets (log.)

$11.0 \quad 56.0 \quad 20.3$

20.3

33.3

$14.2 \quad 145.6$

Number of observations:

$\min -\max$

$1.8 \quad 1.7$

1.7

$817-834$

$888-915$

$660-689$

a The values are normalized by the value of assets, $\%$

Note: In the parentheses under the coefficients, their robust standard errors are given. $>c(<c)$ - the censored variable: it takes values if they are higher (lower) than $c$ and 0 otherwise. 
As shown in our previous study (Mamonov, 2017b), the censored variable has the greatest explanatory power as it reflects all events of banks' increased reliance on both taking household deposits and, at the same time, an increased share of corporate loans in their total assets (compared with median values for the banking system). As can be seen in the table of descriptive statistics below, this concurrence only became more pronounced in time. This could not help affecting the profitability of banking operations, as shown by the negative dynamics of the second variable in the table. This variable reflects all the events of banks showing both an increased share of corporate loans in their total assets and a decreased ROE (compared with median values for the banking system). With the profitability of operations falling, incentives to falsify balance sheets could not help growing. These strengthening incentives are evidenced by the change in the third variable in the table. This is a censored variable reflecting all events of both an increased loan loss provisioning (as a percentage of assets) and a decreased share of nonperforming loans (as a percentage of loans). These situations raise suspicion, because, if the quality of loans is better than average for the system, why set aside larger loan loss provisions than average for the system. If the situation improves in the banking sector, this variable should move towards zero. Looking at the fourth and fifth variables, we note a manifold expansion in the turnover of funds in banks' correspondent accounts with the Bank of Russia and repo liabilities. Among more straightforward indicators (from the 6th to the 14th) we note a twofold rise in loan loss provisioning, representing loan quality deterioration, as well as the sluggish movement of assets at both ends of the period under study (an effect of the period being "framed" with the crises).

\section{Evaluation of aggregate HNC using Heckman selection models}

\subsection{Regression analysis results}

A series of 90 sequential estimations of the Heckman selection models (1)-(2) was conducted for each respective month within the time span under analysis, from December 2009 to May 2017. Table 3 presents a part of these estimates: at the end points of the time span and in mid- $2013^{5}$, the time of the Bank of Russia's senior management change. The first column of the table contains all of the 14 microeconomic control variables, for which descriptive statistics were presented in Table 2 above. In the second and third columns there are estimates of the equations of selection (1) and size (2) for the lower boundary of the time span under analysis (model I), in the fourth and fifth - those for the time of the Bank of Russia's senior management change (model II), in the sixth and seventh - those for the upper boundary of the time span (model III). The lower part of the table contains the

\footnotetext{
${ }^{5}$ The rest of the estimates for the other 87 months are not shown for space considerations but are available upon request.
} 
relevant statistics: the number of banks in the reference and fragile groups, the median probabilities in the respective bank groups, and the correlation of regression errors in the equations of selection and size. As is clear from the table, we did not use macroeconomic variables in our final estimations, because we found that their inclusion in the first two years of the time span under analysis causes the estimates of HNC size to move upwards substantially with the coefficient estimates being formally consistent and statistically significant. All the variables used were three-month lagged to provide a signal window.

Table 3. Selection models of bank HNC: estimates at the edges of the available time span and at the time of the Bank of Russia's senior management change

\begin{tabular}{|c|c|c|c|c|c|c|}
\hline \multirow{2}{*}{$\begin{array}{l}\text { Bank-level } \\
\text { explanatory variables, } \\
\text { lag = } 3 \text { months before } \\
\text { license withdrawal }\end{array}$} & \multicolumn{2}{|c|}{1 January 2010 (I) } & \multicolumn{2}{|c|}{1 July 2013 (II) } & \multicolumn{2}{|c|}{1 June 2017 (III) } \\
\hline & Selection & Size & Selection & Size & Selection & Size \\
\hline $\begin{array}{l}\text { Household deposits }{ }^{\mathrm{a}}> \\
\text { 1. median } \times \text { Corporate } \\
\text { loans } \mathrm{s}^{\mathrm{a}}>\text { median }\end{array}$ & $\begin{array}{c}0.0019^{* * *} \\
(0.0003)\end{array}$ & $\begin{array}{l}0.0013^{* *} \\
(0.0006)\end{array}$ & $\begin{array}{c}0.0011^{\star * *} \\
(0.0041)\end{array}$ & $\begin{array}{c}0.0038 \\
(0.0029)\end{array}$ & $\begin{array}{c}0.0007^{* * *} \\
(0.0002)\end{array}$ & $\begin{array}{l}0.0014^{* *} \\
(0.0006)\end{array}$ \\
\hline $\begin{array}{l}\text { Corporate loans }> \\
\text { 2. } \text { median } \times \text { Profit } / \\
\text { capital }<\text { median }\end{array}$ & $\begin{array}{c}-0.029^{* * *} \\
(0.005)\end{array}$ & $\begin{array}{c}-0.015^{*} \\
(0.008)\end{array}$ & $\begin{array}{l}0.004^{*} \\
(0.002)\end{array}$ & $\begin{array}{c}0.008 \\
(0.015)\end{array}$ & $\begin{array}{c}0.008^{* * *} \\
(0.002)\end{array}$ & $\begin{array}{c}0.003 \\
(0.007)\end{array}$ \\
\hline $\begin{array}{l}\text { Loan loss provisions }> \\
\text { 3. } \begin{array}{l}\text { median } \times \mathrm{NPL}< \\
\text { median }\end{array}\end{array}$ & $\begin{array}{c}0.007 \\
(0.007)\end{array}$ & $\begin{array}{l}-0.005 \\
(0.018)\end{array}$ & $\begin{array}{c}0.020^{* * *} \\
(0.005)\end{array}$ & $\begin{array}{c}0.065 \\
(0.067)\end{array}$ & $\begin{array}{c}0.013^{* * *} \\
(0.005)\end{array}$ & $\begin{array}{c}0.023 \\
(0.022)\end{array}$ \\
\hline $\begin{array}{l}\text { Monthly turnovers } \\
\text { 4. in corresp accounts } \\
\text { with Bank of Russia, \% }\end{array}$ & $\begin{array}{c}0.000 \\
(0.000)\end{array}$ & $\begin{array}{c}0.002^{* * *} \\
(0.001)\end{array}$ & $\begin{array}{c}0.000 \\
(0.000)\end{array}$ & $\begin{array}{c}0.001 \\
(0.001)\end{array}$ & $\begin{array}{c}0.000 \\
(0.000)\end{array}$ & $\begin{array}{l}0.0018^{\star *} \\
(0.0007)\end{array}$ \\
\hline $\begin{array}{l}\text { 5onthly turnovers } \\
\text { in repo liabilities, \% }\end{array}$ & $\begin{array}{c}0.020 \\
(0.015)\end{array}$ & $\begin{array}{c}-0.104^{* *} \\
(0.048)\end{array}$ & $\begin{array}{c}0.015 \\
(0.012)\end{array}$ & $\begin{array}{l}-0.068 \\
(0.086)\end{array}$ & $\begin{array}{l}-0.009 \\
(0.014)\end{array}$ & $\begin{array}{c}-0.133^{* * *} \\
(0.050)\end{array}$ \\
\hline $\begin{array}{l}\text { Household loans / } \\
\text { Assets, \% }\end{array}$ & $\begin{array}{c}0.006 \\
(0.005)\end{array}$ & $\begin{array}{l}-0.026 \\
(0.017)\end{array}$ & $\begin{array}{c}-0.008^{\star} \\
(0.004)\end{array}$ & $\begin{array}{l}-0.056 \\
(0.036)\end{array}$ & $\begin{array}{l}-0.008 \\
(0.005)\end{array}$ & $\begin{array}{l}-0.028 \\
(0.017)\end{array}$ \\
\hline $\begin{array}{l}\text { 7. Absolutely liquid } \\
\text { assets / Assets, } \%\end{array}$ & $\begin{array}{l}-0.005 \\
(0.007)\end{array}$ & $\begin{array}{l}-0.011 \\
(0.024)\end{array}$ & $\begin{array}{l}-0.003 \\
(0.006)\end{array}$ & $\begin{array}{l}-0.010 \\
(0.035)\end{array}$ & $\begin{array}{l}-0.041^{* * *} \\
(0.007)\end{array}$ & $\begin{array}{l}-0.036 \\
(0.029)\end{array}$ \\
\hline $\begin{array}{l}\text { 8. Corporate securities / } \\
\text { Assets, } \%\end{array}$ & $\begin{array}{c}0.006 \\
(0.024)\end{array}$ & $\begin{array}{c}0.064 \\
(0.066)\end{array}$ & $\begin{array}{l}-0.015 \\
(0.018)\end{array}$ & $\begin{array}{l}-0.018 \\
(0.115)\end{array}$ & $\begin{array}{c}0.101^{\star * *} \\
(0.032)\end{array}$ & $\begin{array}{l}0.158^{\star} \\
(0.086)\end{array}$ \\
\hline $\begin{array}{l}\text { 9. Due from IB market / } \\
\text { Assets, } \%\end{array}$ & $\begin{array}{l}-0.003 \\
(0.008)\end{array}$ & $\begin{array}{l}-0.035 \\
(0.028)\end{array}$ & $\begin{array}{c}-0.026^{\star * *} \\
(0.008)\end{array}$ & $\begin{array}{l}-0.125 \\
(0.093)\end{array}$ & $\begin{array}{c}-0.038^{* * *} \\
(0.008)\end{array}$ & $\begin{array}{c}-0.058^{*} \\
(0.033)\end{array}$ \\
\hline $\begin{array}{l}\text { Foreign liabilities / } \\
\text { Liabilities, \% }\end{array}$ & $\begin{array}{c}-0.061^{\star * *} \\
(0.016)\end{array}$ & $\begin{array}{c}0.080 \\
(0.049)\end{array}$ & $\begin{array}{l}-0.014 \\
(0.009)\end{array}$ & $\begin{array}{c}0.061 \\
(0.078)\end{array}$ & $\begin{array}{l}-0.008 \\
(0.009)\end{array}$ & $\begin{array}{l}0.099^{* *} \\
(0.048)\end{array}$ \\
\hline 11. Capital / Assets, \% & $\begin{array}{c}-0.028^{* * *} \\
(0.008)\end{array}$ & $\begin{array}{c}-0.130^{* * *} \\
(0.027)\end{array}$ & $\begin{array}{c}-0.016^{\star *} \\
(0.007)\end{array}$ & $\begin{array}{c}-0.155^{\star * *} \\
(0.056)\end{array}$ & $\begin{array}{c}-0.037^{* * *} \\
(0.008)\end{array}$ & $\begin{array}{c}-0.111^{* * *} \\
(0.024)\end{array}$ \\
\hline $\begin{array}{l}\text { Loan loss provisions / } \\
\text { Loans, } \%\end{array}$ & $\begin{array}{c}0.030^{* * *} \\
(0.007)\end{array}$ & $\begin{array}{c}0.011 \\
(0.021)\end{array}$ & $\begin{array}{c}0.006^{\star * *} \\
(0.002)\end{array}$ & $\begin{array}{c}0.004 \\
(0.026)\end{array}$ & $\begin{array}{c}-0.009^{\star *} \\
(0.004)\end{array}$ & $\begin{array}{l}-0.039^{*} \\
(0.020)\end{array}$ \\
\hline
\end{tabular}

${ }^{a}$ values are normalized by the value of assets, $\%$ 


\begin{tabular}{|c|c|c|c|c|c|c|}
\hline \multirow{2}{*}{$\begin{array}{l}\text { Bank-level } \\
\text { explanatory variables, } \\
\text { lag = } 3 \text { months before } \\
\text { license withdrawal }\end{array}$} & \multicolumn{2}{|c|}{1 January 2010 (I) } & \multicolumn{2}{|c|}{1 July 2013 (II) } & \multicolumn{2}{|c|}{1 June 2017 (III) } \\
\hline & Selection & Size & Selection & Size & Selection & Size \\
\hline $\begin{array}{l}\text { 13. Annual as } \\
\text { rate, } \%\end{array}$ & $\begin{array}{l}0.004^{* *} \\
(0.002)\end{array}$ & $\begin{array}{c}0.030^{* * *} \\
(0.006)\end{array}$ & $\begin{array}{c}-0.004^{\star *} \\
(0.002)\end{array}$ & $\begin{array}{c}0.009 \\
(0.018)\end{array}$ & $\begin{array}{c}0.007^{\star * *} \\
(0.002)\end{array}$ & $\begin{array}{c}0.031^{* * *} \\
(0.007)\end{array}$ \\
\hline 14. Assets (log.) & $\begin{array}{l}0.136^{* *} \\
(0.056)\end{array}$ & & $\begin{array}{l}-0.043 \\
(0.005)\end{array}$ & & $\begin{array}{c}-0.348^{* * *} \\
(0.059)\end{array}$ & \\
\hline Constant & $\begin{array}{c}-1.353^{* * *} \\
(0.288)\end{array}$ & $\begin{array}{c}3.594^{* * *} \\
(1.021)\end{array}$ & $\begin{array}{c}-0.483^{*} \\
(0.270)\end{array}$ & $\begin{array}{l}-0.975 \\
(5.203)\end{array}$ & $\begin{array}{c}1.501^{\star * *} \\
(0.323)\end{array}$ & $\begin{array}{c}3.697^{\star * * *} \\
(0.962)\end{array}$ \\
\hline
\end{tabular}

Banks in operation on this date / banks with HNC detected $661 / 152$ $735 / 152$ $508 / 152$ by 1 July 2016

Likelihood of detecting HNC (median): failed banks / operating banks
$0.19 / 0.51$
$0.17 / 0.32$
$0.23 / 0.48$

HNC size (times as large as capital, median): $3.3 / 3.9$ $3.3 / 3.8$ $3.3 / 3.9$ actual / model

Correlation between errors in equations of selection and size

$0.54^{* *} \quad 1.00 \quad 0.75^{* *}$

${ }^{* * *}, * *$
parentheses
punder the coefficients are their robust standard errors.

Note: The table presents two-step effective estimates of Heckman model. The dependent variables are: the likelihood of detecting a bank $H N C$ - in the selection equation, the relative size of $\mathrm{HNC}$ - in the size equation.

In the parentheses under the coefficients their robust standards errors are shown. $>c(<c)$ - the censored variable. It takes values if they are higher (lower) than $c$ and 0 otherwise.

The key estimation results are as follows. First, Heckman selection models successfully address the problem of identifying bank HNC throughout the 90 months of the time span under analysis, but two conditions of identification were not met for about 20 months of the 2012-2013 period (the assets variable in the selection equation and the correlation of errors in the equations of selection and size were not significant, see Section 2). This means that consistent coefficient estimates can be achieved using not only the effective two-step Heckman procedure but also by other available methods. We present Heckman estimates for all the segments of the time span under analysis for comparability reasons. In comparing the estimates of detection likelihood and the size of the predicted HNC, we can see that at the time span borders the estimates of HNC detection likelihood were substantially higher than those in the middle of the time span: around 50\% in December 2009 and May 2017 versus 32\% in June 2013, while the estimates of the 
median HNC size were roughly stable in time. This in itself suggests that (a) HNC as a phenomenon were inherent in the Russian banking system at least 3.5 years before the senior management change at the Bank of Russia; (b) there was a very high probability of identifying these HNC and (c) the signs of the median HNC size declining are yet to be seen (meaning that the banking sector cleanup from unscrupulous players has yet to be completed).

Second, the estimates themselves allow ranking all the variables by their statistical significance for explaining HNC. Variables 1, 2, 11, and 13 are, for instance, significant throughout the time span, variables 3 and $9-$ in its second half, variables $4,5,10$, and 14 - at both edges of the time span. We are therefore refining the findings of our previous study (Mamonov, 2017b) and concluding that variables I and II are the most stable in time indicators of HNC. They signal that the likelihood and size of HNC were the higher throughout the time span, the higher, relative to the system's averages, were the share of retail deposits in liabilities and that of corporate loans in assets (variable I) and the larger was the shortfall of a bank's own resources (variable II).

Third, we have also obtained noteworthy results regarding other variables. Specifically, if a bank had an increased share of both loan loss provisions and, at the same time, a reduced share of nonperforming loans (relative to the system in both events), then, beginning from the second half of the time span under analysis, this consistently evidenced the existence of a "hole" in its capital but was not very informative for evaluating its size (variable 3). Meanwhile, the level of loan loss provisioning (variable 12) itself was positively correlated with the selection likelihood in the first half of the time span and negatively in its the second half. This may indicate banks' changing attitude towards loan loss provisioning thanks to the new policy of the Bank of Russia's new senior management to eliminate the banking sector's problems accumulated over the previous years. Before the management change, banks' decisions concerning provisioning may have been quite arbitrary and, therefore, positively correlated with the likelihood of HNC. By contrast, in the second half of the time span under study, when banks began to understand that the Bank of Russia may visit them any time for inspection, provisions began to perform their function. As a result, if provisions have already been set aside, a bank is better protected from micro- or macroeconomic shocks and features a proportionally lower likelihood and a smaller size of HNC. Another finding regards liquidity. If a bank has an adequate supply of liquidity (variable 7) and is a net creditor in the interbank market (variable 9), the likelihood of HNC becomes lower, and the size of this HNC if it has been found, - smaller. Finally, there is a countercyclical relationship between the annual change in bank assets and the likelihood and size of HNC. For instance, during macroeconomic crises (or in the vicinity thereof) an increased asset growth rate is positively correlated with both of the above indicators for HNC, while times of economic growth see their negative correlation, as very much expected. 


\subsection{Calibration of probability threshold under the maximization of the regulator's utility function}

The preceding stage of this study has provided estimates of two panel data series: those of detection probability and size of HNC at banks still in operation in each of the 90 months of the time span under analysis. Now we need to determine what HNC sizes can be deemed indistinguishable from zero and which cannot. Under the methodology employed (see Section 2), we will carry this out using the detection probability threshold computed based on the regulator's utility function (3).

The results of solving the regulator's optimization problem are presented in Figure 1 for three prescribed sets determining the regulator's preferences (unknown to us) regarding the importance of attributing a bank to the reference or fragile group.

Figure 1. Results of the regulator's utility function estimation

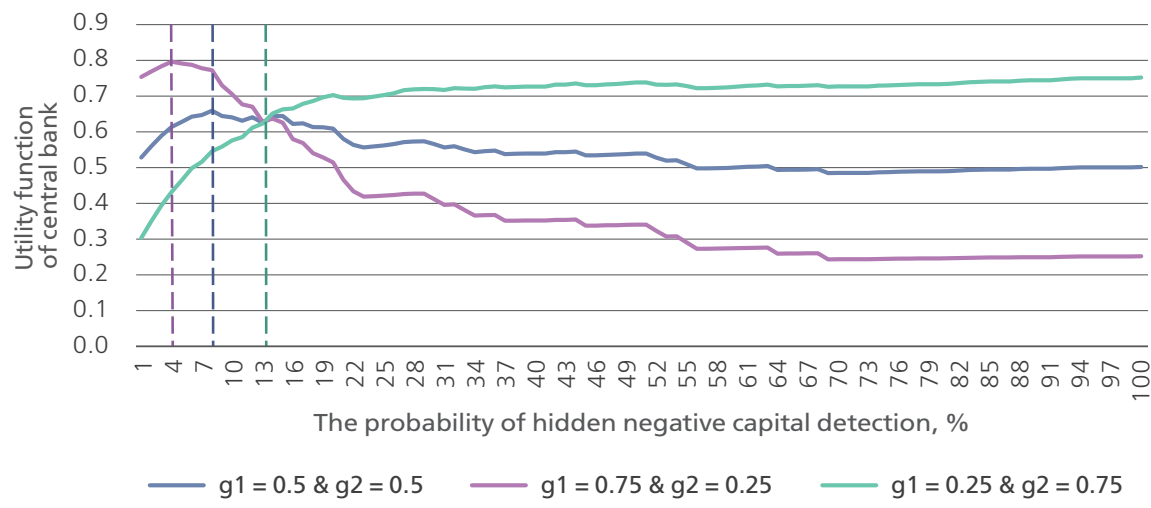

Weighted average sum of shares of accurately predicted events of HNC presence ("1") and absence ("0"); the weights are equal to the preset values of the regulator's unknown preferences; a 6-month forecast period.

The first set, where the regulator views correctly attributing banks to both the fragile and reference group as equally important (weights $\gamma_{1}=\gamma_{2}=0.5$ ), yields the utility function whose maximum is achieved at a detection probability level of $8 \%$ $(p=0.08)$.

The second set, where the regulator views correctly attributing a bank to the fragile group as more important (weights $\gamma_{1}=0.75, \gamma_{2}=0.25$ ), determines the regulator's utility function whose maximum utility corresponds to a softer threshold than in the preceding case, that of $4 \%,(p=0.04)$.

The third set, in which the regulator views correctly attributing a bank to the reference group as more important (weights $\gamma_{1}=0.25, \gamma_{2}=0.75$ ), represents a utility function whose maximum expectedly goes to the upper probability bound at $100 \%$ $(p=1)$. This option is noninformative for our further analysis. But we note that at a threshold of $13 \%$ ( $p=0.13)$ there is an intersection of all of the three options, meaning that all the choices result in the same level of the regulator's utility. 
Thus, we have three candidates for the role of the optimal threshold $p^{*}$. We will now compare the predictive capability of selection model (1)-(2) for each of them and choose the best of the available options. The comparison results are shown in Table 4, in the first panel of which the predictions of the presence/absence of HNC (values $A(p), B(p), C(p)$ and $D(p)$ ) are shown and the shares of accurately predicted events of HNC presence/absence are computed, while the second panel shows estimates of HNC size for each case given in the first panel and those of the shares of accurately predicted HNC sizes in their actual total size identified by the regulator in the first half of 2016.

Table 4. Bank HNC: out-of-sample forecast for a 6-month time span

\begin{tabular}{|c|c|c|c|c|c|}
\hline \multicolumn{6}{|c|}{ HNC in model } \\
\hline Yes & No & Yes & No & Yes & No \\
\hline Thre & $-4 \gamma$ & \multicolumn{2}{|c|}{ Threshold $=\mathbf{8 \%}$} & \multicolumn{2}{|c|}{ Threshold = 13\% } \\
\hline
\end{tabular}

Panel 1: Prediction of HNC detection

Actual HNC in 1H 2016

\begin{tabular}{ccccccc}
\hline Yes & 42 & 1 & 38 & 5 & 27 & 16 \\
\hline No & 522 & 172 & 395 & 299 & 264 & 430 \\
\hline $\begin{array}{l}\text { Share of accurately predicted } \\
\text { events of HNC presence, } \%\end{array}$ & 97.7 & & 88.4 & & 62.8 & \\
$\begin{array}{l}\text { Share of accurately predicted } \\
\text { events of HNC absence, } \%\end{array}$ & & 37.7 & & 56.0 & & 73.4 \\
\hline
\end{tabular}

Panel 2: prediction of HNC size, bln rubles

Actual HNC in $1 \mathrm{H} 2016$

\begin{tabular}{ccccccc}
\hline Yes & 253 & $402 / 1$ & 161 & $190 / 213$ & 133 & $176 / 227$ \\
\hline No & 6443 & & 2309 & & 1131 & \\
\hline
\end{tabular}

Size of accurately predicted $\mathrm{HNC}, \%$

$62.8 / 62.7$

$84.6 / 39.9$

$74.9 / 32.9$

For reference:

Actual size of $\mathrm{HNC}$ detected by regulator over $1 \mathrm{H} 2016=403.4$ bln rubles

Note: Panel 2 presents the results of an out-of-sample forecast of the HNC size using selection model (1)-(2). For instance, at a threshold of 4\% the model predicts $253 \mathrm{bln}$ ruble-worth total HNC detected by the regulator at 43 banks in the 1st half of 2016. The actual size of these HNC totals 402 bln rubles. The model failed to predict a 1 bln ruble HNC at one bank. So the share of accurately predicted HNC over this period stood at $62.8 \%=253 /(253+402) \times 100$ for banks which the model correctly identified and $62.7 \%=253 /(253+402+1) \times 100$ for all events which the model identified and failed to identify. The rate of success for the other two threshold values is calculated in a similar manner. 
As the estimation results show, on the one hand, a threshold value increase goes along with a pronounced contraction in the share of accurately predicted HNC and their size, and, on the other hand, this is accompanied by a rise in the share of accurately predicted events of their absence. If we were to decide on an optimal threshold of $4 \%$ this would produce a prediction of almost totally accurate prediction of HNC in still operating banks but also a fairly low share of accurately predicted events of their absence - slightly above 1/3. If, conversely, we were to use the most rigid of the three thresholds, $13 \%$, we would see the opposite situation. Hence an intermediate threshold of $8 \%$ looks like a reasonable compromise. It yields a still high share of accurately predicted HNC but already a hefty $56 \%$ share of accurately predicted events of their absence. We will therefore settle on $p^{*}$ as an optimal threshold. At this threshold, the share of predicted size of HNC in their overall volume for the 38 banks at which the model correctly detected the presence of HNC (panel 1) stood at $85 \%$. In other words, the model fairly accurately predicts the size of $\mathrm{HNC}$ if it detects its presence at a bank. The model, however, failed to recognize HNC at the other 5 banks (panel 1), whereas the regulator actually found there were such HNC for a total of 213 bln rubles, i.e., these are quite large banks. So, the share of accurately predicted volume of HNC in the overall size of both those the model detected and those it failed to detect stands at just $40 \%$. Undoubtedly, this is a limitation in terms of our analysis, which should be addressed in further studies. This suggests that the problems of large banks are hidden from the regulator much more carefully and are much harder to find out statistically - from a sample comprising primarily small banks (large banks have access to a wider array of accounting manipulations compared with small banks, including transborder manipulations with the balances of correspondent accounts at foreign banks, etc.). For now, we will not try to refine the results we have obtained but will assume that subsequent estimates of the overall HNC size may be too conservative. However, this exercise is informative in any case, as it shows the least amount of losses society suffers because of unfair competition in the banking system.

\subsection{Change in banks' HNC and the probabilities of their detection before and after the Bank of Russia's senior management changed: is the situation improving?}

Having estimated Heckman selection models and quantified probability thresholds, we can now move on to constructing dynamic series of HNC and probabilities of detecting thereof over the December 2009 - May 2017 period. In each of these 90 months, the resulting total of HNC included all observations for which model (2) predicted a nonzero HNC and model (1) predicted an at least 8 -percent likelihood of detecting it. The results of this estimation are presented graphically in Figure 2 below as a percentage of the banking system's total assets on 
a specific date. In addition to the dynamics of HNC, two points in time are indicated: mid-2013, when the Bank of Russia's management changed, and mid2016, the time when the fragile group was made up. This is the key point of this study. In analyzing the dynamics, we obtained relative to the above two points in time, we can draw the following conclusions:

First, prior to the change in the Bank of Russia's senior management, the average level of HNC was very high - 14\% of the banking system's total assets, and quite stable in time but showed pronounced volatility, varying between $10 \%$ and $16 \%$.

Second, as early as a year after the Bank of Russia's senior management changed, the level of HNC started to decline, falling to $4 \%$ by mid-2016, i.e., by four times over three years. Meanwhile mid-2015 saw a surge from 5\% to $10 \%$ - this was exactly when the model started to predict HNC at the Otkritie Financial Corporation and a number of other Russian financial institutions, some of which successfully dealt with their problems - or hid them in an even more sophisticated manner.

Third, in the last 12 months of the time span under analysis the level of HNC stabilized at $4 \%$.

Figure 2. Estimation of HNC at still operating banks prior to and after the senior management's change at the Bank of Russia (excluding the top-5 governmentowned banks), as a percentage of the banking system's total assets

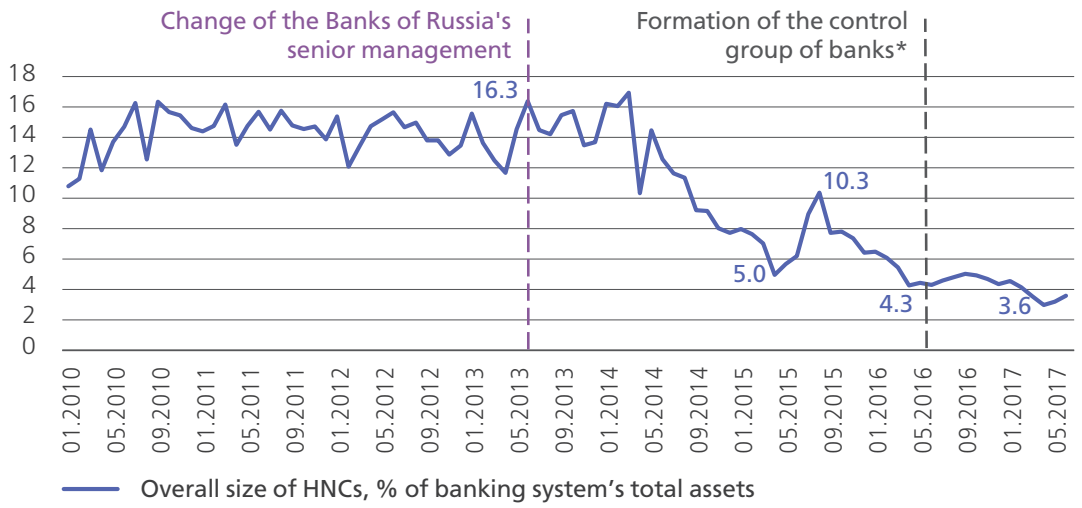

\footnotetext{
* The total size of HNC is estimated by comparing profiles of banks from the fragile (with HNC) and control (without HNC) groups (Section 2). The fragile group was made up of all banks for which the size of HNC could be found in The Bank of Russia Bulletin by mid-2016 and which were subjected to standard outlier filtration.
}

How are these empirical findings to be interpreted? In our view, they support the conclusions of numerous studies to the effect that problems have accumulated for years in Russia's banking system given the lack of drastic policy measures to eliminate unscrupulous players from the banking sector. It is noteworthy that before the senior management change at the Bank of Russia the amount of HNC was quite substantial and stable in time, let alone close to zero. The phenomenon of HNC is not something newly emerged amidst dim economic prospects or Western sanctions against Russia. The above numbers point to the strong effectiveness of the new senior management's measures, which helped reduce the 
relative level of HNC fourfold. Moreover, the impact of their reduction can be decomposed into direct and indirect effects. As is known - and pointed out in the Introduction - over the time the new management were taking action, detected HNC totaled an equivalent of $2.5 \%$ of the banking system's assets, while the overall effect amounts to $16 \%-4 \%=12 \%$. This suggests a substantial indirect effect: in anticipation of supervision policy toughening, banks which still operated but already encountered problems had to start addressing them on their own by cleaning their balance sheets from toxic assets and/or scaling down their loans to related parties without waiting for the Bank of Russia to show up. In other words, banks which were able to deal with their problems on their own have already done so, while the ones incapable of resolving the situation will face the regulator. As the change in the relative level of HNC suggests, the indirect effect has already petered out, meaning that banks which keep hiding HNC will likely be found fairly fast.

We will now deal with the distribution dynamics of probabilities of detecting HNC (Figure 3). It can be seen that in the period from mid-2013 to early 2017 the median probability exceeded the selected $8 \%$ optimal threshold, i.e., more than half of banks in operation may have concealed their HNC. It is only towards the middle of the period under analysis that the median probability fell below the threshold along with the probability value at the lower percentiles of distribution. On the one hand, this clearly points to the cleanup of the banking system, but on the other hand, indicates that the regulator will have to take greater efforts to uncover such HNC at banks which continue concealing their problems. It is noteworthy that probability values at higher percentiles of distribution, by contrast, rise in time. This shows that model (1)-(2) "learns" with time, making it easier for the regulator to uncover HNC if banks rely on similar methods to hide them.

Figure 3. Estimating the probability of detecting $\mathrm{HNC}$ at still operating banks (excluding the top- 5 government-owned banks)

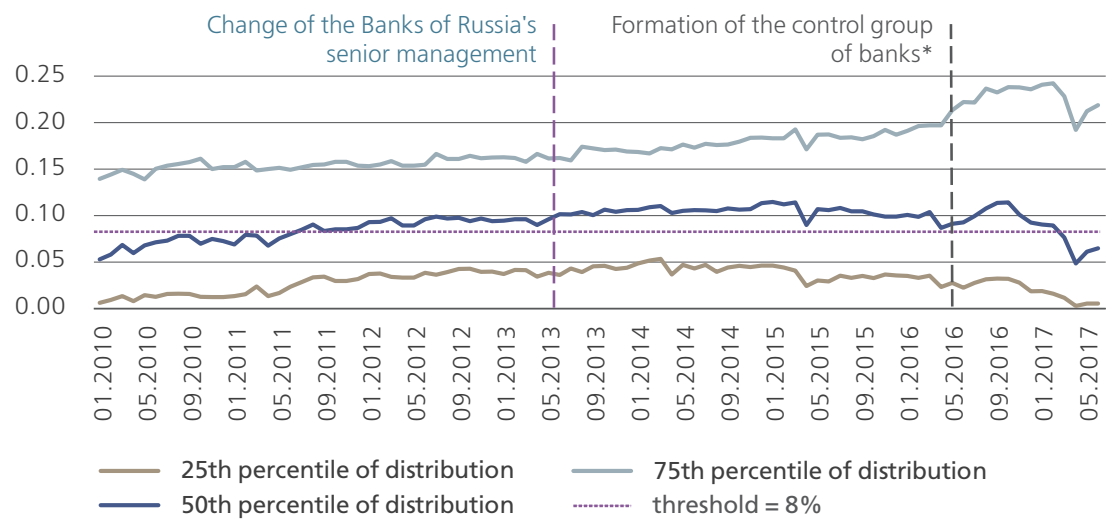

\footnotetext{
* The total size of HNC is estimated by comparing profiles of banks from the fragile (with HNC) and control (without HNC) groups (Section 2). The fragile group was made up of all banks for which the size of HNC could be found in The Bank of Russia Bulletin by mid-2016 and which were subjected to standard outlier filtration.
} 
In conclusion we will briefly speculate on factors which may have contributed to the above-mentioned positive indirect effect of the Bank of Russia's new policy. Table 5 presents average values of HNC at banks still in operation for the three periods analyzed above and two possible factors unrelated to the Bank of Russia's measures. The first of them reflects aggregated macroeconomic conditions, the second represents the profitability of the banking sector itself. Did the second and third periods (II and III) really see a macroeconomic upturn versus the first period (I), which could have triggered a profitability rise (I)? As calculations show, the HNC contraction in the second period took place concurrently with both a macroeconomic downturn and a drop in the profitability of banking operations. In the third period, the situation with profitability was not different from that in the first but the macroeconomic environment at least stabilized at a low level. This means that the indirect effect in question is of course partly due to factors unrelated to the Bank of Russia's measures. But this part is hardly large enough to account for the magnitude of the indirect effect. We are inclined to believe that this positive indirect effect, after all, stems from the Bank of Russia's measures.

Table 5. Bank HNC, profitability of the banking system's assets, and GDP growth rate

\begin{tabular}{l|c|c|c|}
\hline Value (period-average) & $\begin{array}{c}\text { Jan 2010 - } \\
\text { June 2013 } \\
\text { (I) }\end{array}$ & $\begin{array}{c}\text { July 2013 - } \\
\text { June 2016 } \\
\text { (II) }\end{array}$ & $\begin{array}{c}\text { July 2016 - } \\
\text { May 2017 } \\
\text { (III) }\end{array}$ \\
\hline $\begin{array}{l}\text { Total size of HNC at still operating } \\
\text { banks (excluding top-5 government- } \\
\text { owned banks), \% of banking system's } \\
\text { total assets }\end{array}$ & 14.2 & 9.6 & 4.2 \\
\hline $\begin{array}{l}\text { 12-month moving average profit / } \\
\text { Banking system's total assets, \% after } \\
\text { loan loss provisions (ROA) }\end{array}$ & 1.8 & 1.0 & 1.1 \\
\hline $\begin{array}{l}\text { 12-month moving average GDP } \\
\text { growth, \% }\end{array}$ & 3.6 & -0.5 & 0.5 \\
\hline
\end{tabular}

\section{Conclusion}

What was the size of HNC in the Russian banking system before the Bank of Russia's senior management changed? Has the financial regulator's new, tougher, supervision policy launched in mid-2013 been productive in dealing with problems accumulated over recent years? This study attempts to provide initial answers to these questions using Heckman selection models and solving a possible regulator's optimization problem based on December 2000 - May 2017 Russian bank data. We analyzed two groups of banks: the fragile and reference ones. The former was made up of all credit institutions for which The Bank of Russia Bulletin published official data on uncovered HNC; we fixed this sample in time. The latter, on all dates from December 2009 to May 2017, comprised all banks in operation, 
some of which were hiding HNC from the regulator. We varied this sample in time relative to the fixed fragile group and attempted to find out the size of their HNC.

We can sum up our findings as follows. Before the Bank of Russia's senior management changed in mid-2013, the average level of HNC at banks operating in Russia was very high: $14 \%$ of the banking system's total assets on each specific date, and fairly permanent in time. However, as early as half a year after the Bank of Russia's senior management changed, the overall size of these HNC started contracting rapidly, coming close to $4 \%$ by mid-2016. In the last 12 months of the time span under study the level of the HNC stabilized at $4 \%$. These estimates point to the high effectiveness of the new senior management's tough supervision policy. This policy has produced a strong indirect positive effect: part of fragile banks have started addressing their problems without waiting for the Central Bank to show up. The effectiveness of the Bank of Russia's new policy cannot be attributed to third factors such as macroeconomic stabilization or improvement and/or rising profitability of bank operations. Rather, when supervision policy was stepped up, both of the above third factors were acting in the opposite direction.

\section{References}

Balla, E., Prescott, E.S., Walter, J. (2015). Did PCA Fail? A comparison of bank failures and FDIC losses in the 1987-92 and 2007-13 periods. FRB-Richmond working paper WP15-05.

Bernanke, B., Gertler, M. (1989). Agency costs, Net Worth, and Business Fluctuations. American Economic Review, 79(1), pp. 14-31.

Brown, C., Dinç, I.S. (2005). The politics of bank failures: evidence from emerging markets. The Quarterly Journal of Economics, 120(4), pp. 413-444.

Brown, C., Dinç, I.S. (2011). Too many to fail? Evidence of regulatory forbearance when the banking sector is weak. The Review of Financial Studies, 24(4), pp. 1378-1405.

Chen, N.-K. (2001). Bank net worth, asset prices and economic activity. Journal of Monetary Economics, №38, pp. 415-436.

Cole, R.A, White, L.J. (2015). When Time Is Not on Our Side: The Costs of Regulatory Forbearance in the Closure of Insolvent Banks. Social Science Research Network. Series SSRN Working Paper Series, №2694556.

DeYoung, R., Torna, G. (2013). Nontraditional banking activities and bank failures during the financial crisis. Journal of Financial Intermediation, №22, pp. 397-421.

Diamond, D.W., Dybvig, P.H. (1983). Bank Runs, Deposit Insurance, and Liquidity. The Journal of Political Economy, 91(3), pp. 401-419.

Diamond, D.W., Rajan, R.G. (2000). A Theory of Bank Capital. The Journal of Finance, 55(6), pp. 2431-2465.

Drobyshevsky, S., Zubarev, A. (2011). Factors of Russian banks' reliability in 2007-2009. Proceedings of Gaidar Institute for Economic Policy, №155P, pp. 1-108.

Heckman, J. (1979). Sample selection bias as a specification error. Econometrica, 47(1), pp. 153-161. 
James, C. (1991). The losses realized in bank failures. The Journal of Finance, 46(4), pp. 1223-1242.

Kaminsky, G.L., Reinhart, C.M. (1999). The Twin Crises: The Causes of Banking and Balance-of-Payments Problems. American Economic Review, 89(3), pp.473-500.

Karminsky, A.M., Kostrov, A.V. (2013). Models of default probabilities for Russian banks: enhanced opportunities. Journal of the New Economic Association, 17(1), pp. 64-86.

Kang, A., Lowery, R., Wardlaw, M. (2015). The cost of closing failed banks: A structural estimation of regulatory incentives. The Review of Financial Studies, 28(4), pp.1060-1102.

Kiyotaki, N., Moore, J. (1997). Credit cycles. The Journal of Political Economy, 105(2), pp.211-248.

Mamonov, M.E. (2017a). «Holes» in the Capital of Failed Russian Banks: Old Indicators and New Hypotheses. Ekonomicheskaya Politika, 12(1), pp. 166-199.

Mamonov, M.E. (2017b). Hidden "holes" in the capital of not yet failed banks in Russia: An estimate of the scope of potential losses. Voprosi Ekonomiki, №7, pp. 42-61.

Peresetsky, A.A. (2013). Modeling causes of license withdrawals from Russian banks. Impact of unaccounted for factors. Applied Econometrics, 30(2), pp. 49-64.

Wheelock, D., Wilson, P. (2000). Why do banks disappear? The determinants of U.S. bank failures and acquisitions. The Review of Economics and Statistics, 82(1), pp.127-138. 